\title{
El acto de escribir en la universidad. Una experiencia a partir de la autobiografía'
}

\author{
The Act of Writing at University. An Experience from Autobiography
}

\author{
JOEL OSWALDO VIELMA RONDÓN \\ Universidad de Los Andes \\ Venezuela \\ joelvielma.I5@gmail.com
}

(Recibido: 29-06-2020; aceptado: 2I-IO-2O2O)

Resumen. Escribir en el entorno universitario requiere del acompañamiento y la orientación del docente. Es evidente que la composición escrita no puede ser planteada únicamente como un deber apartado de las necesidades e intereses de los estudiantes. El estudio que se muestra a continuación tuvo como propósito que un grupo de siete estudiantes de formación docente, con una carrera profesional previa, pudiera vivenciar el proceso de escritura a partir de la construcción de una autobiografía. En este sentido, se logró relacionar el aprendizaje de los subprocesos implicados en el acto de escribir con la producción de un relato autobiográfico que generó espacios para que afloraran la subjetividad y la introspección. Se adoptó un enfoque cualitativo y etnográfico que permitió detallar cambios positivos en los textos elaborados, de acuerdo con una secuencia de borradores o versiones intermedias. Se concluye que la escritura en la universidad requiere de situaciones didácticas específicas que conduzcan a los estudiantes a reflexionar y a redimensionar el papel que cumple la lengua escrita, no solo en cuanto al manejo de los géneros discursivos, sino también en la construcción de su propia voz y en la reafirmación de su identidad como seres sociales y culturales.

Palabras clave: enseñanza de la escritura; identidad; relato.
Abstract. Writing in the university environment requires the accompaniment and guidance of the teacher. It is clear that written composition cannot be approached solely as a duty apart from the needs and interests of the students. The purpose of the following study is that a group of seven students of in training to be teachers, with previous professional careers, could experience the process of writing from the construction of an autobiography. In this sense, it was possible to relate the learning of the subprocesses involved in the act of writing with the production of an autobiographical story that generated spaces for subjectivity and introspection to emerge. A qualitative and ethnographic approach was adopted, which made it possible to detail positive changes in the texts produced, according to a sequence of drafts or intermediate versions. It was concluded that writing at the university requires specific didactic situations that lead students to reflect on and re-dimension the role that written language plays, not only in terms of the handling of discursive genres, but also in the construction of their own voice and in the reaffirmation of their identity as social and cultural beings.

Keywords: teaching writing; identity; story

\footnotetext{
${ }^{\text {I }}$ Para citar este artículo: Vielma Rondón, Joel Oswaldo (2O2I). El acto de escribir en la universidad. Una experiencia a partir de la autobiografía. Alabe 24. [www.revistaalabe.com]

DOI: IO.I5645/Alabe2O2I.24.4
} 


\section{Introducción}

Cuando los estudiantes ingresan a la universidad traen consigo una carga experiencial que entreteje factores motivacionales, afectivos, académicos y culturales en sus historias de vida. Particularmente, sus experiencias previas como lectores y escritores de diferentes tipos de textos hacen que cada uno desarrolle nociones individuales acerca de lo que implica leer y escribir en el entorno académico universitario. Sin embargo, estos conocimientos no siempre se corresponden con lo que el docente demanda y espera. Es así como se extiende una brecha difícil de acortar entre ambos agentes y que marca en el devenir académico una actitud desfavorecedora de parte del estudiante hacia la lectura y, con mayor énfasis, hacia el acto de escribir.

En la mayoría de los casos, el docente asume que la escritura es un saber adquirido o una habilidad generalizada producto del recorrido estudiantil por los anteriores niveles del sistema educativo (Ramírez, 20I7). Esta preconcepción hace que quien enseña opere desde una visión de la escritura concebida como un producto (Hernández y Quintero, 200I). Sin duda, quedan limitadas de forma considerable las posibilidades de mejora en los estudiantes y la labor pedagógica puede volverse punitiva y distante, ya que el enfoque se sitúa sobre la evaluación de los textos y su calificación. En virtud de este panorama, valdría la pena preguntar ¿Cómo podrían incorporarse los componentes subjetivos y afectivos del estudiante dentro de las experiencias que propone el docente para el aprendizaje de la escritura en las aulas universitarias?

En este artículo se pretende mostrar los resultados de una intervención didáctica realizada con estudiantes de la Licenciatura en Educación del Programa de Profesionalización Docente de la Universidad de Los Andes (en adelante PPD), en el estado Mérida, Venezuela. Este programa tiene como rasgo particular el hecho de atender a personas que ya poseen un título de pregrado a nivel de Técnico Superior Universitario o de Licenciatura (carrera larga) en áreas distintas a la pedagogía, pero que laboran dentro del Sistema Educativo o aspiran ingresar en él. En este caso, los participantes provenían de una carrera larga y cursaron la asignatura titulada Seminario Opcional (Lectura y Escritura). Dicho seminario tiene por objetivo favorecer competencias en torno a la lectura y la escritura para aprender en la universidad.

De acuerdo con lo antes expuesto, la investigación se propuso analizar los avances en el proceso de escritura de un grupo de estudiantes de Educación a partir de la construcción de una autobiografía. Se seleccionó este género por hacer parte del programa de la materia y porque facilitaría el diálogo intersubjetivo, la manifestación de intereses, inquietudes y valoraciones compartidas en torno al acto de escribir. Este último argumento se fraguó como un criterio de novedad para plantear un trabajo de corte cualitativo y etnográfico que vinculó la subjetividad de los estudiantes, emanada de sus experiencias vitales, con el aprendizaje de la lengua escrita como una actividad procesual, flexible y recursiva. 


\section{La escritura vista como un proceso en la universidad}

La escritura propuesta como una actividad de aprendizaje en la universidad devela en los estudiantes sus contradicciones e inseguridades. Así mismo, hace perceptible el manejo que tienen de las propiedades textuales, sus niveles de comprensión y su capacidad crítica y reflexiva. Estos requerimientos se entraman con las consignas docentes, planteadas en muchas ocasiones para ser vividas desde el alejamiento y la soledad, impidiendo que el estudiante asuma el acto de escribir como una actividad real con capacidad para transformar sus posibilidades como sujeto de discurso, ubicado en unas coordenadas espaciales y temporales específicas.

Es importante recordar que diversas investigaciones en torno a la lingüística, la psicología cognitiva y la pedagogía, iniciadas en las últimas décadas del siglo XX y que se prolongan hasta la actualidad, han venido determinando que la escritura es un proceso que implica reflexionar y que requiere de espacios recurrentes para la planificación, textualización, revisión y edición de los textos (Scardamalia y Bereiter, I992; Flower y Hayes, I996; Cassany, r996; Cassany, Luna y Sanz, ı998; Cassany, r999; DIDACTEXT, 2003; Carlino, 2004 y Álvarez, 2005). En las líneas subsiguientes se plantearán de modo sucinto los subprocesos que, activados de forma recursiva y dinámica, se involucran en el proceso de composición escrita para aprender a manejarlo con propósito, sentido y pertinencia. Al respecto, Álvarez (2005) describe la planificación, la textualización y la revisión en estos términos:

Planificación: se refiere a la contextualización de la actividad de escritura para delimitar intencionalidades, registro a utilizar, destinatario/s y efectos que se desea conseguir en él/ellos. Es una fase que sirve para reunir información, esquematizarla o darle algún tipo de organización. Es el momento de proyectar ideas que luego se van a unir a la capacidad de inventiva y de creación del escritor.

Textualización: implica la organización sintáctica y gráfica del texto para otorgarle la pertinencia semántica y pragmática. Las ideas que se vislumbraron en el plan de trabajo inicial pasan ahora a formar parte de los borradores o textos intermedios. Se requiere de un trabajo constante de lectura y escritura a medida que se va avanzando. Es preciso que en el desarrollo de este subproceso se pueda prestar suficiente atención a las propiedades textuales como un eje constitutivo de cualquier texto escrito.

Revisión: contempla la resolución de problemas a nivel local y global en el texto, es decir, tanto a nivel de las oraciones como del texto en su conjunto. Es necesario detectar los desajustes en la superficie (fallas ortográficas y gramaticales, problemas de referencia, repeticiones) y en la estructura profunda (planteo de ideas, argumentos, fallas de contenido, contradicciones). La revisión obliga a quien escribe a considerar la situación retórica en su totalidad: interpretación del texto, reflexión y producción textual. 


\section{La autobiografía: subjetividad y retrospectiva a través de la escritura}

La autobiografía se encuentra impregnada de un alto nivel de subjetividad por parte de quien escribe y representa una valiosa oportunidad para contar a otros una trayectoria de vida marcada por tensiones, sentimientos, deseos y recuerdos de diferente índole. Es entonces un texto dialógico e intersubjetivo que se desplaza desde lo íntimo hacia la recepción de un destinatario. Quien escribe una autobiografía evoca de modo autorreferencial su devenir histórico y cultural en el seno de una familia y de una comunidad de pertenencia. Estos espacios de acción humana adquieren centralidad, por cuanto dejan una impronta en el sujeto/escritor y le ayudan a construir su propia identidad, develada a través de la escritura, tal y como ocurre dentro del género autobiográfico. Al tratar de conceptualizar la autobiografía, resulta pertinente citar a Maganto (2OIO, p. II5) quien explica lo siguiente:

La palabra autobiografía proviene del griego $\alpha v \tau$ tó $\varsigma$ autos= «propio», $\beta$ ío $\varsigma$ bios= «vida» y $\gamma \rho \alpha ́ \varphi \varepsilon \imath v$ grafos= «escritura», lo que significa la narración de una vida o la historia hecha por la propia persona sobre ella misma, mostrando su nacimiento, orígenes, acontecimientos importantes, experiencias personales destacables, logros y fracasos.

De manera pues, que las narrativas autobiográficas se asientan sobre la cronología y relevancia de los hechos que le suceden a una persona, por lo que recogen a partir de un esfuerzo cognitivo elementos de orden social, psicológico y afectivo orquestados en una prosa que pasa por un inicio, un desarrollo y un cierre temporal (la circunstancia actual del autor como sujeto y protagonista de la narración). Al respecto, Lejeune (citado por Rodríguez, 200o) afirma que se trata de relato con carácter retrospectivo, organizado en prosa, que una persona hace de su propia existencia, enfatizando su vida individual y la historia de su personalidad.

De forma análoga, Madriz (2004) expresa que la autobiografía es un ejercicio de retrospección sobre la vida de un individuo, mezclando aspectos de la realidad objetiva, subjetiva e intersubjetiva, ya que cuando una persona se narra a sí misma se asumen nuevas significaciones construidas en un espacio simbólico culturalmente compartido. Los autores convocados coinciden al valorar la autobiografía como un ámbito lingüístico vinculante entre el escritor y su mundo. Allí, el protagonista analiza sus relaciones consigo mismo y la implicancia de los factores externos que le circundan como unidades modelizadoras de su espacio personal.

Desde un punto de vista pedagógico, la autobiografía sitúa al estudiante frente a una actividad que le exige un compromiso personal y académico para encauzar sus asuntos privados a través de la palabra construida, armonizada y dirigida a uno o más lectores que comparten con él un espacio de formación. Por lo tanto, contribuye para que vaya delineando su propio perfil como escritor, su estilo, su modo de ser y presentarse a los demás por medio de los textos que elabora. Para Gutiérrez (2OIO), la escritura es “un acto 
esencial para re-construir, re-crear, re-narrar la propia existencia y, al hacerlo, esbozar una voz propia" (p. 363). De tal suerte, que la construcción de estas narrativas favorece la identidad sociodiscursiva del que escribe para relatar su existencia y hacerse visible para sus destinatarios en un tiempo y circunstancia particulares. En relación con esta idea, Navarro (20I8) agrega que "la escritura pone en juego la valoración, identidad e ideología de los escritores y muestra trazos de los contextos sociales, históricos y culturales en los que se manifiesta” (p. 2I).

Finalmente, debe recordarse la imprescindible conexión que existe entre los factores internos del estudiante y la consecusión de los aprendizajes. Es difícil lograr que este se apropie del conocimiento y lo transforme si no se le motiva o inspira, si no se le confronta con su propia vida. Gil (I997) manifiesta que cuando se descartan los componentes personales de la teoría y la praxis educativa, la situación que se genera está literalmente indeterminada dado que se obvian los elementos internos y subjetivos de las relaciones humanas.

Es probable que algún lector de este artículo se pregunte en qué contextos de la formación superior es viable la escritura de relatos autobiográficos, vale decir entonces, que este género no está reservado únicamente para quienes incursionan en las Ciencias de la Salud, las Ciencias Sociales y las Humanidades, pues todos los estudiantes comparten una característica esencial: son seres del lenguaje y lo utilizan, recordando a Vygotsky (I995), como uno de los instrumentos de mediación cultural más importantes y que determina la construcción de su propia realidad. Quienes aprenden poseen una carga histórica, social y familiar que se activa en cada experiencia vivida y que puede servir para hacer prospectiva en el accionar pedagógico.

\section{El contexto de la investigación}

La asignatura Seminario Opcional (Lectura y Escritura) se encuentra ubicada en el primer semestre del plan de estudios del PPD. Esta unidad curricular busca potenciar las competencias necesarias para la formación de lectores y escritores autónomos. Al mismo tiempo, pretende aumentar la sensibilidad pedagógica de los participantes alrededor de estos saberes, debido a su preparación académica como futuros docentes. Por tales razones, se trabaja de modo intensivo en actividades que exigen hablar, escuchar, leer y escribir como procesos cognitivo-lingüísticos.

La intervención didáctica se realizó durante el primer trimestre del semestre B-20I6. En total fueron ocho encuentros presenciales, cada uno contó con cinco horas académicas de duración (la última hora de cada clase fue dedicada al taller de escritura creativa). El grupo en su conjunto se mostró desde el principio interesado en la asignatura, por consiguiente, hubo la disposición para participar en todas las actividades planteadas. En este sentido, se informó a los estudiantes en el primer encuentro que la autobiografía representaría la evaluación final y que, por tanto, requerirían comenzar con 
antelación el proceso de composición escrita. En aras de poner la actividad en un marco real de acción, se trazaron los siguientes objetivos:

Objetivos general: analizar los avances en el proceso de escritura de un grupo de estudiantes de Educación a partir de la construcción de una autobiografía.

\section{Objetivos específicos:}

- Revisar los aspectos teóricos más relevantes de la autobiografía situando sus características conceptuales y discursivas.

- Generar espacios de reflexión en actividades concurrentes de lectura y escritura dirigidas a la construcción de una autobiografía.

- Identificar las mejoras en los relatos autobiográficos de los estudiantes y sus implicaciones en los modos de concebir el acto escritural en la universidad.

En la segunda sesión el investigador explicó las convenciones de la autobiografía, apoyándose en la exposición de material gráfico (presentación de Power Point) y en la entrega de material instruccional. En la tercera sesión se mostraron fragmentos de algunas autobiografías tales como "Confieso que he vivido" de Pablo Neruda (I974), "Vivir para contarla” de Gabriel García Márquez (2004) y “Un ensayo autobiográfico” de Jorge Luis Borges (I999). La lectura de autores reconocidos, además de resultar una actividad literaria profundamente enriquecedora, sirvió para dialogar acerca de la sensibilidad humana y el sentido estético de la vida que estos escritores fueron capaces de imprimir en sus obras.

Así, el marco generado por la situación didáctica exigió a los estudiantes dar inicio desde estos primeros encuentros a la planificación de sus textos, en función de una guía de preguntas planteada por el docente. De esta guía de preguntas se destacan las siguientes: ¿De qué aspectos de mi vida voy a hablar?, ¿para qué lo voy a hacer?, ¿cómo lo voy a hacer?, ¿cómo me presentaré a los receptores o destinatarios?, ¿cómo voy a articular mis experiencias vitales con un lenguaje literario? En paralelo, se les solicitó hacer en sus cuadernos un inventario de sucesos personales, familiares, académicos y profesionales que merecían y debían ser contados para poder engranar sus narrativas y hacerlas comprensibles para los lectores.

Los encuentros restantes se dedicaron a leer, escribir y comentar los avances de las autobiografías (los estudiantes accedieron a compartir e intercambiar sus borradores). Aunado a ello, las versiones preliminares y la edición del texto fueron atendidas por el docente a través del correo electrónico. Las estrategias pedagógicas implementadas a lo largo del proceso facilitaron la reflexión y comprensión de la secuencia textual narrativa, sobre todo, para poder considerarla como la urdimbre sobre la cual se tejen los textos autobiográficos. 


\section{Marco metodológico}

En la investigación participaron siete (o7) estudiantes que estaban optando por el título de Licenciados en Educación mención Ciencias Sociales, todos provenían de una carrera larga. En la tabla $\mathrm{N}^{\circ}$ I se muestran los nombres ficticios (para proteger la identidad de los estudiantes), el título profesional y la ocupación para el momento en el que se desarrolló la experiencia.

Tabla I. Distribución de los participantes

\begin{tabular}{|c|c|c|}
\hline Nombre & Título universitario & Ocupación \\
\hline Fabiola & Criminólogo & Docente \\
\hline Alberto & Abogado & $\begin{array}{c}\text { En libre ejercicio de la } \\
\text { profesión }\end{array}$ \\
\hline Jimena & Abogado & Registradora civil \\
\hline Martín & Arquitecto & Estudiante \\
\hline Lucía & Ingeniero de gas & Supervisora en una fábrica \\
\hline Reina & Politólogo & Estudiante \\
\hline Edith & Contador público & Asistente contable \\
\hline
\end{tabular}

Fuente. Elaboración propia

Como puede observarse, se trató de un grupo de estudiantes variado (con edades comprendidas entre los veinticuatro y cincuenta años), dedicado a actividades laborales y personales distintivas.

La investigación se inscribe en un marco cualitativo, ya que el interés estuvo centrado en describir de manera amplia una experiencia real, vivida y comunicada por sus propios participantes (Bernal, 20IO). Por ello, desplegaron algunas situaciones de enseñanza orientadas a que los estudiantes pudieran vivenciar el proceso de composición. Así, el acto de escribir en la universidad fue planteado de un modo cercano a la subjetividad de los estudiantes y a su configuración como seres sociales y culturales. Se empleó un diseño etnográfico con el propósito de seguir de cerca las impresiones del grupo y lograr la comprensión global de la situación (Aguirre, I997). Todo ello, de acuerdo con los insumos obtenidos en el aula.

En cuanto a las técnicas de recolección de la información, se manejó la observación participante y el análisis de contenido (borradores de la autobiografía, el texto definitivo y un texto reflexivo adicional solicitado a cada estudiante). Se llevaron a cabo entrevistas no estructuradas y se realizó un registro en notas de campo de todas las incidencias ocurridas. 


\section{Presentación y análisis de los resultados}

Como se mencionó en apartados anteriores, la autobiografía se convirtió en el trabajo final de la unidad curricular y esto condujo a la elaboración de varios borradores, allanando el camino para experimentar de forma amplia los procesos de planificación, textualización, revisión y edición de los textos. A continuación se mostrarán los resultados en dos secciones: en primer lugar, se comparten algunos fragmentos del primer borrador y de la versión final de tres estudiantes, acompañados de un análisis descriptivo en cada caso. La selección de los tres estudiantes y sus textos obedece al hecho de considerar que estos "recortes autobiográficos" son los que mejor ilustran los obstáculos y avances en la escritura, así como en la construcción de una voz propia. En segundo lugar, se analizan algunas reflexiones de los participantes en torno a la escritura y a la autobiografía, surgidas en un momento posterior a la secuencia de actividades.

\section{I Elaboración de las autobiografías: avances en la producción escrita}

Estudiante: Edith

Borrador $\mathrm{N}^{\circ} \mathrm{I}$

No sé cómo, ni cuándo, se conocieron los seres que me dieron la vida, tengo esa gran intriga de saber cómo lo hicieron; pero no hay nadie quien me lo cuente. Lo único que sé es que en medio de un hogar muy humilde, lleno de mucho amor y gran respeto me senté en el vientre de mi madre, en un caserío que estaba rodeado de montañas, alli había mucha tranquilidad sólo se escuchaba el silbido de los pájaros, el suave viento y el fuerte ruido del río Santo Domingo, esta localidad es llamada el Limoncito, perteneciente a un lugar reconocido por sus hermosos paisajes acompañado del frio y sus destacados hoteles: Santo Domingo. Nueve meses después en el octavo día del mes de Junio del año 1986, mi recordada y extrañada madre me dio la vida, supongo este fue uno de los tantos días más felices para mis padres, el lugar donde nacífue en un pueblo muy cercano a Santo Domingo, este pueblo es mucho más frío que donde me crie se llama Mucuchíes, ubicado en los páramos del Estado Mérida. Durante mi infancia, que es la que suelo recordar, fueron mis primeros seis años los días más felices de mi vida, al lado de mis dos hermanos mayores y mi hermana menor, recuerdo a mi madre en su máquina de coser haciéndole ropa a sus hïos y a mi padre cargando leña en su camionetica...

\section{Versión final}

Hay intrigas que uno no puede resolver nunca, por eso, se debe aprender a vivir con ellas. En mi historia personal, puedo contar que no sé cómo, ni cuándo, se conocieron mis padres. Lo único que sé es que en medio de un hogar humilde, pero lleno de mucho amor y respeto, me asenté para venir a pasar nueve meses en el vientre de mi madre. Vivíamos en un caserío que estaba rodeado de hermosas y 
verdes montañas, alli había mucha tranquilidad, sólo se escuchaba el silbido de los pájaros, el ir y venir de un viento meláncolico, y el ruido del río Santo Domingo, esa localidad maravillosa se llama El Limoncito y pertenece a Santo Domingo, un lugar turístico, reconocido por sus envidiados paisajes y por sus destacados hoteles. Retomando el momento de mi nacimiento, diré que en el octavo día del mes de junio del año 1986, mi recordada y extrañada madre me dio la vida, supongo este fue uno de los días más felices para ella y también para mi padre. Nací en Mucuchies, este es un pueblo muy cercano a Santo Domingo, pero mucho más frío y nublado, en comparación con el rinconcito donde me crié. Mis primeros seis años de vida, se convirtieron en los más felices de mi vida. De toda mi infancia estos son los que suelo recordar con mayor nostalgia: era feliz y yo no lo sabía. Tenía a mi lado mis dos hermanos mayores y mi hermana menor. Recuerdo a mi madre, amable y amorosa, sentada en su máquina de coser haciéndole ropa a sus hijos y a mi padre, protector y vigoroso, cargando leña en su camionetica...

Edith comenzó su relato de un modo muy particular: contando una anécdota que luego enlazó con sus primeros años de vida, combinando percepciones, sensaciones y sentimientos evocados en torno al hogar y el espacio geográfico de su origen. Se aprecia un esfuerzo por adjetivar y representar a través del lenguaje las remebranzas de sus primeros años de existencia. Sin embargo, las ideas entremezcladas y los problemas de referencia al momento de narrar ciertos acontecimientos hicieron del primer borrador un texto confuso y repetitivo. En este primer esbozo hizo falta una adecuada organización y separación de las ideas, así como la delimitación de pausas y el cierre de algunas frases para otorgarle mayor sentido a sus proposiciones.

En su versión definitiva la anécdota inicial sirvió de ancla para desplegar una narración personal mucho más consistente y ordenada, sobre todo, en lo relativo a los datos que ubican al lector en tiempo y espacio. Las descripciones del paisaje y el ambiente hogareño permiten que el destinatario se traslade a un entorno rural profundamente atractivo. A través de la escritura Edith logró manifestar sus sentimientos de añoranza y dejó entrever cómo la elaboración del texto escrito la condujo a un proceso de cuestionamiento e instrospección cuando afirmó, por ejemplo: “era feliz y yo no lo sabía". La versión final muestra sus avances en la ordenación de ideas, en la reformulación de las palabras para referir hechos y sentimientos en una secuencia, que a pesar de sus "idas y venidas", no perdió la ilación ni la correspondencia. 
Estudiante: Fabiola

Borrador $\mathrm{N}^{\circ} \mathrm{I}$

Un 26 de septiembre de 1965 vine al mundo, en la maternidad de Mérida de esta tierra de montañas engalanadas con sus cinco águilas cubiertas de nieve. Llevo por nombre Fabiola. Mi padre hombre robusto, corpulento, de tez morena mientras que mi madre medianamente delgada, color de piel blanca que le hacen juego a la cabellera blanca ya por las canas, tengo tres hermanos, dos hembras y un varón en total.

Tuve una infancia muy bonita, tranquila, cálida, primero viví en Belén, la escuela quedaba a unos pasos de donde vivía, al terminar la jornada escolar, nos íbamos mi hermana la menor y yo a jugar en la plaza del frente de mi casa, hacíamos cometas, jugábamos pelota y patinábamos...

Versión final

En las vísperas de un 26 de septiembre de 1965, vine al mundo. Me cuentan que era una mañana soleada y brillante. Nací en la Maternidad de Mérida, en esta tierra de montañas engalanadas por la brisa fresca y sus picos, mejor conocidos como las cinco águilas blancas, cubiertos de fina nieve (reconozco que al observarlas, el frío me hiela el cuerpo). Llevo por nombre Fabiola. Mi padre era un hombre robusto, de tez morena, mientras que mi madre, quien aún vive, ha sido siempre medianamente delgada, de piel blanca como su cabellera, ya por las canas que adornan su cabeza. Tengo tres hermanos: dos hembras y un varón que vino a equilibrar un poco nuestra relación en el hogar.

Tuve una infancia muy bonita, sobre todo tranquila y cálida. En los primeros años viví en un sector de la ciudad llamado Belén, la escuela quedaba a unos cuantos pasos de la casa, por lo cual iba y venía con gran facilidad y sin mucho apuro. Mi hermana menor fue mi cómplice de juegos y tremenduras...

Fabiola comenzó su primer borrador de manera muy directa aportando datos sobre su nacimiento. En lo sucesivo, describió su percepción de la ciudad de Mérida en cuanto a sus principales rasgos geográficos y ofreció también ciertos detalles sobre sus padres. Sin embargo, en este primer apartado dispuso una serie de informaciones exhibidas en cadena, sin separar las oraciones. En el segundo párrafo abundaron los adjetivos para describir sus años de infancia y persistió la combinación de la información.

Aunque no se perciben cambios sustanciales entre el primer borrador y el texto final, en este último hubo una separación más evidente de las ideas y, sin aminorar su conexión, pudo expresarlas con un mejor ritmo, exteriorizando subjetivamente lo que el texto evocaba en ella misma. Además, la autora ordenó los hechos de tal manera que combinó el pasado y el presente sin causar desajustes. Asomó el surgimiento de la conciencia del lector (Cassany, I996), por cuanto las revisiones de los borradores sirvieron para que 
se ubicara en una prosa más cercana al destinatario y ofreciera detalles importantes para entender el relato.

Estudiante: Martín

Borrador $\mathrm{N}^{\circ} \mathrm{I}$

Llegada la noche fría de un 4 de Noviembre del año 199o, tras ocultarse el sol poco a poco entre las ramas de los árboles, dio lugar a mi nacimiento dentro de la habitación principal de mi hogar, labor llevada a cabo bajo la ayuda de una partera. Vivencia que desde mis inicios no resulto ser tan armónica, ya que a pocos meses de mi llegada como nuevo mucutuyero, me toco partir sobre los brazos de mi madre y la compañía de mi padre, hacia la ciudad de Mérida; lugar donde permanecí por más de tres meses hospitalizado, debido a problemas de salud, a los cuales no sé por que razón o circunstancia no auguraban mejoría. Al pasar los años para sorpresa medica mi enfermedad desapareció, tal vez por la fe puesta en Dios o por uno de tantos remedios caseros (bebedizos) ingeridos, ya que una madre desesperada no tiene límites para luchar por sus hïos, y si por salud se refiere aún más; pues a ciencia cierta no sé qué elimino mis problemas de asma, pero dicha interrogante aún sigue presente.

Versión final

En un lugar apartado, al sur del estado Mérida, entre montañas y ríos se disemina un denso páramo andino, cubierto de frailejones y fauna silvestre. Al recorrer sus parajes, se desprende el gran valle de la Veguilla, y a solo minutos de allí sobre un valle florido, se alza bordeando el río de aguas serenas, un pueblo escondido de gente laboriosa y muy risueña. Su nombre es Mucutuy -lugar sagrado de las piedras- las cuales, según la leyenda, dominan el poblado, brindándole protección y cobijo a la gente trabajadora, cuyo quehacer cotidiano se desarrolla alrededor de la agricultura y el cultivo de café, sobre grandes y singulares serranías teñidas de un verde muy especial. Si la ocasión lo permite, podría usted encontrarse con el tucán azul, que solo en este lugar puede verse volar con magnífica soltura, como fondo visual a antiguas casas de corredores techados, alineadas a orillas del río que corre en dirección al sur, después de regar con sus aguas el fértil suelo mucutuyero. [...] Al caer la noche fría del 4 de noviembre del año 199o, el sol se ocultó entre las ramas de los árboles, dando paso a la misteriosa oscuridad y la luna plateada como fiel visitante, reflejó su cara en el río. Tal escenario, dio lugar a mi nacimiento, en medio de las cuatro paredes de tapia de la habitación principal de mi hogar. Las labores de parto fueron resueltas con la ayuda de una partera de nombre Juana, quien gracias a su experiencia, logró que mi madre me diera la bienvenida. Mivida, en sus inicios, no resultó ser tan armónica, ya que a pocos meses de mi llegada como nuevo mucutuyero, me tocó partir en brazos de mis padres 
hacia la ciudad de Mérida. Allí permanecí por más de tres meses hospitalizado, debido a problemas de asma. Nadie me auguraba mejoría. Para sorpresa médica, con el pasar de los años, mi enfermedad desapareció...

Como sucedió con el primer borrador de Fabiola, Martín comenzó el primer avance del texto ofreciendo información acerca de su nacimiento, vinculando su llegada al mundo con un acontecimiento penoso como resulta ser una enfermedad. Hizo mención de su gentilicio "mucutuyero", pero este no es un dato lo suficientemente claro como para que cualquier lector pudiera ubicarse en el contexto de la narración. Se observaron fallas de acentuación. Aunque hay tres grandes cuerpos de ideas en tres oraciones que hacen parte de la introducción, estas pudieron desgranarse en enunciados más cortos.

A diferencia del primer borrador, la versión final mostró un panorama mucho más amplio y detallado que sirvió de telón de fondo para presentar un texto que resultó ser muy interesante y que, en todo sentido, fue progresando a medida que se desarrolló. Martín descubrió desde el principio, y con un aire bucólico, los aspectos geográficos que rodean su pueblo natal. Aportó una visión toponímica y a la vez artística de los parajes descritos para conectar directamente con el lector, al escribir, por ejemplo: "podría usted encontrarse con el tucán azul, que sólo en este lugar puede verse volar”. La narración acerca de su nacimiento fue enmarcada en un ambiente nocturno, y a pesar de la dureza de los días posteriores, se mantuvo en el texto un aura de optimismo. El estudiante seleccionó marcas discursivas adecuadas para la construcción de los textos literarios: "En un lugar apartado" "se alza bordeando el río de aguas serenas", "Al caer la noche fría". Los problemas de acentuación fueron resueltos. La narrativa autobiográfica se apoyó en la sucesión prototípica de inicio, desarrollo y cierre.

\subsection{Nuevos modos de concebir y abordar la escritura en los estudiantes}

La elaboración de la autobiografía sirvió de escenario para trabajar de manera integral el proceso de escritura, comenzando desde la planificación del texto hasta llegar a su edición final, pasando en este transcurso por la producción de varios borradores. Como bien afirma Romagnoli (2018), cuando el escritor planifica, escribe y revisa lo escrito, el resultado es una textualidad diferente. Tales diferencias se hacen palpables en la pertinencia, los ajustes y adecuaciones exteriorizadas en la versión definitiva de las narraciones de los estudiantes. Como puede verse a través de los fragmentos presentados, ellos experimentaron transformaciones en su modo de presentar-se, contar-se y retratarse en sus textos. El ejercicio de escribir de una manera genuina por medio de la autobiografía, los puso frente a la necesidad de analizar su propia identidad. En cuanto a este último aspecto, Madriz (2004), manifiesta de manera muy acertada, que la identidad se constituye en un constante fluir de lectura, escritura e interpretación, pues la vida misma tiene el formato de una narración que, a su vez, tiene huellas de los demás relatos.

Sin duda, que la experiencia los puso de manera indirecta en la situación de auto-

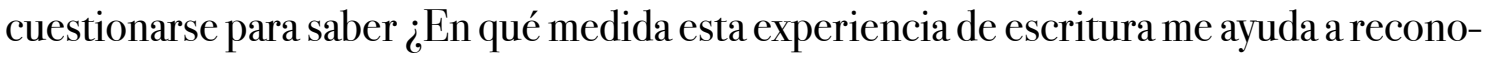


cerme y reforzar mi propia identidad? Esta interrogante les dio razones acerca del sentido del propio aprendizaje (Gil, I999). La propuesta de trabajo en torno a la autobiografía facilitó que estos y otros asuntos se pusieran sobre la mesa para ser discutidos de forma grupal.

Por lo tanto, se conectó una situación de escritura en sus aspectos textuales, retóricos y discursivos con el componente afectivo y personal de los participantes adentrándolos en su dimensión más intíma, al tiempo que accedían a otras subjetividades humanas. Al solicitarles la construcción de un texto reflexivo que valorara su experiencia al escribir, hicieron afirmaciones como las siguientes (por razones de espacio, solo se seleccionaron fragmentos escriturarios):

Reina: "Este trabajo me puso en una situación complicada, porque tuve que enfrentar otra vez aspectos y momentos de mi vida que he querido olvidar, ya sea porque me vi lastimada o lastimé a otras personas que amo. Creo que haber podido escribir de esos sentimientos me permitió romper ataduras y entender que gracias a lo vivido soy quien soy ahora. Me siento muy satisfech a con mi autobiografía y con la oportunidad de escribir poco a poco y sin tantas presiones externas... ."

Edith: "Cuando comencé a cursar el seminario tenía otra idea de lo que significa escribir. Siempre he estado muy centrada en escritos más técnicos ya que mi profesión asílo exige, pero reflexionar sobre lo que escribo y cómo lo escribo fue posible cuando se dio la oportunidad de escribir una autobiografía, un texto muy personal pero a la vez muy digno de ser explotado en los salones de clase. Es por eso que pienso que el proceso de escritura debe darse con suficiente tiempo para poder mejorar y con orientaciones de personas que tengan más experiencia...".

Alberto: "En este trimestre reafirmé una opinión que ya tengo desde hace mucho tiempo: escribir es una tarea que merece respeto y valor, no se trata nada más de pensar y llevar el sistema alfabético al papel. Cuando comencé divagué mucho, repetí ideas, las borré y así las fui organizando, creo que coindicir con un profesor que me orientara sin criticarme fue muy útil. Como cualquier actividad que incluya el pensamiento, la escritura de este texto me puso en la tarea de seguir aprendiendo del lenguaje".

Fabiola: “...casi nunca hablo de mí, y hacerlo a través de un texto me costó, lo reconozco, pero al mismo tiempo ha sido una experiencia muy enriquecedora. Tener que volver a lo escrito, releerlo y recibir apoyo y consejo de los compañeros y del profesor fue muy agradable. Esto lo viví por primera vez, a pesar de tener ya una carrera universitaria. El cambio creo que es bastante considerable, de este seminario me llevo que escribir es producir, contar, mostrar, demostrar y no simplemente copiar o repetir".

Lucía: "Puedo decir que la autobiografía me ayudó a mejorar mi manera de expresarme y también de ver lo escrito más allá de buscar una nota que me haga sentir 
feliz o conforme con mi rendimiento estudiantil. Con los borradores y su revisión hasta llegar al trabajo final, logré darme cuenta de que puedo aprender a escribir mejor, con más cuidado, con palabras más bellas o apropiadas, claro que necesito seguir practicando, porque si no perderé lo aprendido en este tiempo tan importante...".

Martín: "Escribir es ahora todo un problema, no en el mal sentido de la palabra problema, sino que se ha convertido en toda una complejidad a considerar para lograr expresarme de manera adecuada. La escritura de la autobiografía permitió sacar de mí ideas, formas, percepciones, sentimientos y palabras que yo ya traía adentro desde hace mucho tiempo y que nadie me había pedido exteriorizar. Lógicamente no fue fácil, pero pude entender que a escribir se aprende todos los días, que es un constante revisar, volver a pensar, describir y poner en el papel aquello en lo que tú crees; es un aprendizaje que se va dando con la vida y a través de este tipo de experiencias académicas".

Jimena: "...yo no creo que ni siquiera en mi primera carrera que es el Derecho y donde se cuida tanto lo que se escribe, me había puesto a pensar así y a enfocarme con tantas ganas en expresarme. Tal vez sea porque hablé de mí, de lo que siento, de lo que viví y vivo junto a mis amigos, familiares y gente que se va cruzando en mi camino, lo cierto es que la escritura tiene para mí un nuevo significado y una nueva forma de practicarla en mi actual etapa de estudios".

Las impresiones de los estudiantes pueden ser analizadas desde dos vertientes distintas, pero profundamente relacionadas. Por una parte, muestran sus reticencias al tratar de relatar sus vidas y cómo la actividad de escribir un texto autobiográfico se convirtió en una puerta de acceso, en un ejercicio liberador que implicó descubrir esa carga subjetiva que traen consigo, situándola en un contexto de producción lingüística que acogió sentimientos de nostalgia, amor, ternura, tristeza, decepción y que hizo aflorar sus recuerdos para darles un matiz estético. Además, hizo posible que se reafirmara su sentido de pertenencia hacia espacios, lugares y comunidades, ya que pudieron evocar sus propios orígenes.

Por otra parte, sus afirmaciones permiten constatar que el grupo, en general, pudo reconsiderar las potencialidades de la escritura como un aprendizaje gradual que requiere de un esfuerzo constante y del acompañamiento de personas que tengan mayor dominio de la competencia comunicativa escrita. Otro aspecto que debe resaltarse es que los estudiantes dejaron de ver la escritura como una actividad mecánica asociada a la repetición de la información, para pasar a entenderla como un aprendizaje constructivo, atravesado por ciertas complejidades que cobran significancia cuando quien produce un texto lo adecúa a un propósito, un género, una audiencia y una situación específica. Es decir, cuando logra integrar desde un enfoque reflexivo todos los saberes que se activan al escribir (Álvarez, 2005). 


\section{Algunas conclusiones}

Aprender a escribir no es una labor terminada, no se trata de un saber absoluto o ajeno a quien aprende y a quien enseña en la universidad. Las diferencias entre los primeros borradores y las versiones finales de las autobiografías permiten observar que los estudiantes consiguieron un manejo ascendente de los elementos pragmáticos, semánticos, sintácticos y gramaticales de la situación comunicativa escrita. En las entregas finales lograron mantener los referentes y las marcas personales y de modelización, establecieron relaciones causales y pasaron a describir lugares, personas y acontecimientos en un orden cronológico y con una prosa agradable para los lectores. Puede afirmarse entonces, que cada participante se apropió gradualmente de su escrito en la medida que integró relecturas y revisiones. En ese orden de ideas, Urtasun y Domínguez (2020) indican que las reescrituras apoyan el trazado de la voz propia, sobre todo, en las reformulaciones y en los cambios de la forma como materialidad. Por su parte, Obregón (2OI8) reflexiona en cuanto a la voz autoral en los textos humanísticos y declara que en ellos "la autoridad se construye a partir de la visión y la experiencia personal de quien escribe" (p. 229). Las autobiografías ilustran con total nitidez lo dicho por la última autora mencionada, pues en la experiencia pedagógica desplegada los relatos consintieron que los estudiantes exteriorizaran los significados y representaciones que han ido acumulando sobre sí mismos, articulándolos en un discurso profundamente auténtico.

La intersección de la lectura de fragmentos de obras literarias con la producción escrita contribuyó para que los participantes se esforzaran en utilizar recursos literarios identificados en aquellas: descripciones, metáforas, valoraciones subjetivas, entre otros. Albarracín, Jeréz y Encabo (202O) declaran que al combinar la lectura literaria y la escritura creativa, la importancia no se asienta en el texto, sino en el estudiantado que deja de lado su pasividad para pasar a comprender el texto y a generar una nueva historia. La elaboración de narrativas autobiográficas permite concebir el acto de escritura como una actividad creadora, situada en un contexto real y con un alto sentido de pertinencia académica, dado que busca el logro de nuevos aprendizajes y el enriquecimiento de la subjetividad de los estudiantes. 


\section{Referencias bibliográficas}

- Aguirre, Á. (i997). Etnografía. En A. Aguirre (Ed.). Metodología cualitativa en la investigación sociocultural (pp. 3-20). México: Alfaomega.

- Álvarez, T. (2005). Didáctica del texto en la formación del profesorado. Madrid: Síntesis.

- Albarracín, D., Jeréz, I. y Encabo, E. (2020). Composición escrita, influencia mediática y ortografía. Una investigación en las aulas de Educación Primaria. Álabe, 2I, OI-I8. doi:IO.I5645/Alabe2O2O.2I.IO

- Borges, J. (I999). Un ensayo autobiográfico. Barcelona: Galaxia Gutenberg.

- Bernal, C. (20IO). Metodología de la investigación. Bogotá: Pearson Educación.

- Cassany, D. (1996). Describir el escribir. Barcelona: Paidós.

- Cassany, D., Luna, M. y Sanz, G. (1998). Enseñar Lengua. Barcelona: Graó.

- Cassany, D. (1999). Construir la escritura. Barcelona: Paidós.

- Carlino, P. (2004). El proceso de escritura académica: cuatro dificultades de la enseñanza universitaria. Educere $8(26), 3^{2 \mathrm{I}} 32 \mathrm{~F}$.

- DIDACTEXT (2003). Modelo sociocognitivo, pragmalingüístico y didáctico para la producción de textos escritos. Didáctica (Lengua y Literatura), I5, 77-IO4. Extraído el II de enero de 2015 desde http://www.didactext.net/acciones/publicacion.pdf

- Flowers, L. y Hayes, J. (I996). La teoría de la redacción como proceso cognitivo. En Textos en contexto (pp. 75-IIO). Buenos Aires: International Reading Association.

- Gil, F. (I997). Educación y narrativa: la práctica de la autobiografía en la educación. Teoría de la educación, (9), II5-I36. Extraído el o3 de diciembre de 2019 desde https://revistas. usal.es/index.php/II30-3743/article/viewFile/3134/3І62

- Gutiérrez, M. (2OIO). Relato autobiográfico y subjetividad: una construcción narrativa de la identidad personal. Educere, (I4), 36I-37O. Extraído el o6 de marzo de $205_{5}$ desde http:// www.redalyc.org/articulo.oa?id=35617IO2OII

- Hernández, A. y Quintero, A. (2OOI). Comprensión y composición escrita. Madrid: Síntesis.

- Márquez, G. (2004). Vivir para contarla. Barcelona: Editorial Debolsillo. 
- Madriz, G. (2004). ¿Quién eres?... ¿Quién soy? La autobiografía en el relato de lo vivido. A Parte Rei. Revista de Filosofía, 3I, I-8. Extraído el to de febrero de 2020 desde http:// serbal.pntic.mec.es/ cmunozir/gladys3ı.pdf

- Maganto, C. (20Io). La autobiografía. En C. Ibáñez (Coord.). Técnicas de autoinforme en evaluación psicológica. La entrevista clínica (pp. II5-I40). Bilbao: Servicio Editorial Universidad del País Vasco.

- Neruda, P. (1974). Confieso que he vivido. Bogotá: Edinal Ltda.

- Navarro, F. (20I8). Más allá de la alfabetización académica: las funciones de la escritura en educación superior. En M. Alves y V. Iensen (Eds.), Formação de Professores: Ensino, linguagens e tecnologias (pp. I3-49). Porto Alegre: RS Editora. Extraído el I8 de noviembre de 2019 desde https://www.editorafi.org/3o8ufn

- Obregón, C. (20r8). Construir una voz autoral. En F. Navarro y G. Aparicio (Coords.), Manual de lectura, escritura y oralidad académicas para ingresantes a la universidad (pp. 2I7-256). Buenos Aires: Universidad Nacional de Quilmes. Extraído el I8 de noviembre de 20I9 desde https:// ediciones.unq.edu.ar/420-manual-de-lectura-escritura-y-oralidad-academicas-para ingresantes-a-la-universidad.html

- Rodríguez, F. (2000). El género autobiográfico y la construcción del sujeto autorreferencial. Filología y Lingüústica, 26(2), 9-24. Extraído el 25 de octubre de 2017 desde https:// revistas.ucr.ac.cr/index.php/filyling/article/view/45I4

- Ramírez, F. (20I7). Enseñanza de lectura y escritura en comunidades académicas universitarias. Revista Educación Superior y Sociedad, I8, 59-83. Extraído el II de abril de 2019 desde http://www.iesalc.unesco.org/ess/index.php/ess3/article/view/6

- Romagnoli, A. (2018). Leer y escribir en la universidad. En F. Navarro y G. Aparicio (Coords.), Manual de lectura, escritura y oralidad académicas para ingresantes a la universidad (pp. 25-62). Buenos Aires: Universidad Nacional de Quilmes. Extraído el i8 de noviembre de 2019 desde https://ediciones.unq.edu.ar/420-manual-de-lectura-escrituray-oralidad-academicas-para ingresantes-a-la-universidad.html

- Scardamalia, M. y Bereiter, C. (I992). Dos modelos explicativos de los procesos de composición escrita. Infancia y Aprendizaje, 58, 43-64.

- Vygotsky, L. (1995). Historia del desarrollo de las funciones psíquicas superiores. En obras escogidas. Volumen III. Madrid: Visor.

-Urtasun, M. y Domínguez, M. (2020). Con "voz propia”: tensiones entre escritura académica y escritura creativa. Traslaciones. Revista Latinoamericana de Lectura y Escritura, 7(г3), 95-I28. Extraído el 6 de noviembre de 2020 desde https://ng.cl/es/s/tkgvo 